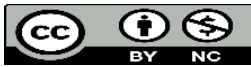

Licenciado sob uma licença Creative Commons

ISSN 2175-6058

https://doi.org/10.18759/rdgf.v19i2.1024

\title{
CIDADANIA INDÍGENA E PLURALISMO JURÍDICO: CRÍTICA AO ESTATUTO DO ÍNDIO
}

\author{
INDIGENOUS CITIZENSHIP AND JURIDICAL PLURALISM: \\ CRITIQUE TO THE INDIGENOUS STATUTE
}

\author{
Luciano Roberto Gulart Cabral Júnior \\ Francisco Quintanilha Véras Neto
}

\section{RESUMO}

Objetiva-se, nesta pesquisa de cunho qualitativo, pelo método de abordagem dedutivo, analisar, sob a luz do pluralismo jurídico, a modelagem da cidadania indígena traduzida no Estatuto do Índio. Diante do enfoque dado pelo multiculturalismo e pelo interculturalismo, constata-se que o Estatuto do Índio assenta a "incapacidade" indígena, baseando-se no eurocentrismo e no colonialismo que conformam o Estado brasileiro. Urge um giro decolonial visando à eliminação da subalternidade dos povos indígenas e à construção de uma cidadania material indígena. Sustentam-se, portanto, a revogação das normas jurídicas que tolhem a cidadania indígena e a articulação de medidas interculturais com a cultura indígena.

Palavras-chave: Cidadania Indígena. Pluralismo jurídico. Estatuto do Índio.

\section{ABSTRACT}

The objective of this qualitative research, through the deductive method, is to analyze, in the light of juridical pluralism, the modeling of indigenous citizenship translated into the Indigenous Statute. Given the focus of multiculturalism and interculturalism, this research shows that the indigenous Statute confirms an indigenous "incapacity" due to Eurocentrism and colonialism that make up the Brazilian State. A decolonial shift is urgently needed to eliminate the 
subalternity of indigenous peoples and to build indigenous material citizenship. Therefore it concludes for the repeal of legal norms that restrain indigenous citizenship and the articulation of intercultural measures with indigenous culture.

Keywords: Indigenous citizenship. Juridical pluralism. Indigenous Statute.

\section{INTRODUÇÃO}

O povo indígena é alvo de violências desde a chegada dos europeus na América Latina. Passados séculos desde a invasão europeia de Pindorama, o Estado brasileiro, por intermédio das normas jurídicas que produz, também demonstra o modo como pretende lidar com os indígenas. Nesse contexto, o Estatuto do Índio é o diploma legal voltado especificamente para os indígenas no Brasil.

Com base em uma pesquisa qualitativa, tendo como método de abordagem o dedutivo, através de pesquisa bibliográfica e legislativa sobre o tema, utilizando-se do método de procedimento monográfico (LAKATOS; MARCONI, 2012, p. 110), analisar-se-á, então, como a cidadania indígena é tratada no Estatuto do Índio, sob a luz do pluralismo jurídico, indagando-se se tal cidadania é vista como ampliada. Isso é relevante porque uma análise crítica sobre a forma como a cidadania dos povos originários do Brasil é considerada pelo Estado brasileiro permite compreender a direção trilhada pelo tratamento dispensado à respectiva população. Dito em outros termos, o Estatuto do Índio expressa, pela sua normatividade, a postura adotada pelo Estado no que concerne a seu povo originário.

Sucintamente, no primeiro capítulo abordam-se aspectos do pluralismo jurídico e do indigenismo no Brasil. No segundo capítulo, detalham-se como a cidadania indígena é vista pelo Estatuto do Índio e como a transversalidade do pluralismo comunitário-participativo pode ser um meio de reforço à dita cidadania.

\section{PLURALISMO JURÍDICO E INDIGENISMO NO BRASIL}

O complexo histórico brasileiro, a miscigenação e a não singularidade das etnias, o convívio cotidiano de inúmeras culturas ${ }^{1}$ dos quatro 
cantos do mundo, a extensão territorial acompanhada de vários brasis dentro do Brasil, a recente democracia, enfim, o mosaico de vivências e identidades pressupõe que a legislação brasileira seja confrontada com as realidades. Nesse palco jurídico, é impossível se dissociar o pluralismo jurídico da análise das relativas questões.

O pluralismo jurídico compreende a negação de que o centro de poder político e a fonte de produção do Direito pertençam unicamente ao Estado. A perspectiva é descentralizadora, antidogmática, pretendendo a supremacia dos fundamentos ético-político-sociológicos sobre critérios tecno-formais positivistas. Tal assertiva se funda precipuamente na percepção da crise e do esgotamento do modelo jurídico liberal-individualista, impotente para propiciar respostas satisfatórias e eficazes aos anseios sociais nas sociedades conflitivas de massas (WOLKMER, 2001, p. 15-16)

Trata-se de perceber que a macroestruturação da desigualdade social oriunda do processo de globalização neoliberal contemporânea imprescinde da proposta de um novo Direito contra-hegemônico, que se direcione a transcender a ordem elitista (positivista, tecnicista, centrada, formalista, conservadora). Daí a relevância ímpar das conquistas políticas e sociais, buscando-se "uma cidadania material concreta e não abstrata, separadora de sujeitos e objetos jurídicos, dentro dos sistemas de trocas formais capitalistas reificadoras, da epistemologia e técnicas jurídicas" (VÉRAS NETO, 2010, p. 162).

No contexto do indigenismo, é inevitável o aporte do pluralismo jurídico. Ora, como sugere Castro (2002, p. 349), enquanto as cosmologias "multiculturalistas" modernas se debruçam na ideia de uma unicidade da natureza e multiplicidade das culturas, a concepção dos ameríndios se baseia na unidade do espírito e na diversidade dos corpos. Por exemplo, etnografias sul-americanas - prossegue o autor - concebem que

[...] o modo como os seres humanos vêem os animais e outras subjetividades que povoam o universo - deuses, espíritos, mortos, habitantes de outros níveis cósmicos, plantas, fenômenos meteorológicos, acidentes geográficos, objetos e artefatos -, é profundamente diferente do modo como esses seres vêem os humanos e se vêem a si mesmos. Tipicamente, os humanos, em condições normais, vêem os humanos como humanos e os animais como 
animais; quanto aos espíritos, ver estes seres usualmente invisíveis é um signo seguro de que as 'condições' não são normais. Os animais predadores e os espíritos, entretanto, vêem os humanos como animais de presa, ao passo que os animais de presa vêem os humanos como espíritos ou como animais predadores [...]. Vendo-nos como não-humanos, é a si mesmos que os animais e espíritos vêem-se como humanos (CASTRO, 2002, p. 350-352).

Além disso, a categoria "indígena" envolve populações diferentes entre si, tanto do ponto de vista biológico, quanto linguístico, como dos costumes (MELATTI, 1983, p. 31-56). O Brasil, portanto, é plural, e a visão centralizadora não se coaduna com as suas diversidades que se entrelaçam, inclusive no interior da própria cultura indígena.

Malgrado, tende-se a subvalorizar a cultura dos chamados "povos primitivos", como lhes atribuir exclusivamente as necessidades orgânicas ou econômicas como força motriz de existência (LÉVI-STRAUSS, 1989, p. 17). Controvertendo tal perspectiva, o pluralismo jurídico é uma via para a integração da cultura indígena às expressões político-jurídicas, ressaltando, inclusive, o princípio democrático, tendo em vista que

[...] a identidade indígena, a pertença cultural do índio é sua condição de existência no mundo, sua forma de existir enquanto homem diferente. Antes de ser índio ele é homem, e o homem não vive sem pertencer a algum lugar, sem exercer seu raciocínio, sem manifestar-se culturalmente, sem satisfazer as necessidades biológicas, sem exercer sua humanidade. As dificuldades da cultura indígena, das condições materiais e simbólicas de sua permanência enquanto povo, está diretamente relacionada aos tratos expropriatórios e violentos que negaram e negam igualdade do índio de poder viver de acordo com sua cultura (LUCAS, 2007, p. 12)

A exasperação do poder social pressupõe a participação de grupos como os agrupamentos indígenas, evidências de "pluralização jurídica comunitária participativa, capazes de empreenderem a construção de uma nova estabilidade, dentro de um novo pluralismo jurídico constitucionalmente legitimado" (VÉRAS NETO, 2010, p. 153). A marca inovadora da América Latina, nessa conjuntura, é a ebulição de novas Constituições (como a do Equador e a da Bolívia) que primam pela plurinacionalidade e pela plurietnia, fundando-se no poder popular e dos povos originários, considerando as contradições derivadas da histórica subalternidade à es- 
trutura eurocentrada das oligarquias detentoras do poder político-econômico. Enfrentou-se dita dominação diante da exaustão ao neoliberalismo e à esquerda tradicional, propiciando novos espaços à manifestação das forças populares. (VÉRAS NETO, 2015, p. 233-234)

No processo de constitucionalização dos Estados da América Latina houve forte influência das Declarações de Direitos e Constituições dos Estados da Europa e dos Estados Unidos da América. Então, da colonização à independência dos Estados latino-americanos observa-se na consolidação das instituições jurídicas essa tradição legal, o que para os povos originários do continente (indígenas, afro-americanos, campesinos, entre outros) significou exclusão de seus interesses e direitos em detrimento das elites hegemônicas notadamente influenciadas pela cultura europeia ou anglo-americana (SCHNEIDER, 2015, p. 93).

O multiculturalismo, combinado com a justiça multicultural e as cidadanias plurais, busca lidar com as tensões entre a diferença e a igualdade, na ótica de reivindicações emancipatórias. Luta-se contra o eurocentrismo da cultura, da justiça, da cidadania, propondo a inclusão das diferenças. Almeja-se o reconhecimento da diferença e a redistribuição da riqueza para permitir a igualdade, a fim de oportunizar a coexistência de culturas nas sociedades contemporâneas (SANTOS; NUNES, 2003, p. 25-26).

Sendo o multiculturalismo definido pela "existência de uma série de culturas diferentes na mesma sociedade", o interculturalismo, nessa toada, "significa interface, troca, intercâmbio, reciprocidade, criação de espaços de participação coletiva entre culturas diferentes" (KROHLING, 2009, p. 104-105). Como salienta categoricamente Panikkar (2004, p. 236-237), haja vista que os direitos humanos não são universais e derivam de uma expressividade da elite ocidental, eles devem permitir que as diversas culturas mundiais desenvolvam e formulem as suas próprias visões acerca dos direitos humanos - seja encontrando espaço intermediário de crítica recíproca e enriquecimento mútuo entre concepções culturais diversas, seja de oposição à orientação ocidental dirigente, exaltando uma filosofia intercultural em prol do pluralismo humano.

Angariando analogicamente as lições de Coutinho (1979, p. 40), numa perspectiva socialista, "democracia é sinônimo de pluralismo", embora a burocracia estatal disfarce a dominação das elites por meio de uma 
suposta neutralidade. A "democracia pluralista de massas" deve inverter essa concepção, enfrentando a alienação do poder com uma autonomia dos sujeitos políticos. Nos ares do constitucionalismo latino-americano da Bolívia, Wolkmer e Ferrazzo (2014, p. 225) aspiram à "democracia comunitária", uma forma de democracia voltada aos interesses populares e comunitários, construída "desde baixo", onde as decisões políticas são tomadas pelas bases da sociedade (e não por elites), procurando transcender a democracia individualista de matiz burguesa e a racionalidade do modelo liberal capitalista.

Dito de outra forma, as concepções não hegemônicas da democracia prezam por negar as formas homogeneizadoras de organização da sociedade, para reconhecer a pluralidade humana, enfatizando uma "nova gramática social e cultural" e a inovação social e institucional. Para tanto, mister a ruptura com a antiga ordem tradicional estabelecida, rumo à democracia participativa. A democracia participativa denota o fortalecimento da demodiversidade, imbricada com o multiculturalismo, apoiado na articulação contra-hegemônica entre o local e o global. Além disso, perpassa-se pela ampliação do experimentalismo democrático para uma pluralização cultural e distributiva da democracia (SANTOS; AVRITZER, 2002, p. 50-78).

A descentralização democrática do Direito talvez permita uma reconstrução das formas de planejamento democrático da máquina estatal, que precisa ser desprivatizada rumo a uma nova estatalidade capaz de conceder direitos (emancipação), efetivando conquistas no plano da igualdade, sem anular o direito libertário da identidade e das diferenças autogeridas pela ampliação da democracia direta/participativa, substantiva, solidária e plural adaptada à nova complexidade policêntrica regida pela alteridade. (VÉRAS NETO, 2010, p. 163)

Conquanto incongruente seja a relativização absoluta dos direitos humanos, impossibilitando o diálogo entre povos e culturas e conduzindo a um confinamento (ilhamento), a universalidade dos direitos humanos, por outro lado, como fator a-histórico, possui o aval do imperialismo ocidental, como uma visão antropocêntrica e eurocêntrica, reverberada pela "síndrome colonialista das potências ocidentais hegemônicas" 
(KROHLING, 2009, p. 99-100). Sob o pretexto dessa universalidade dos direitos humanos, a história revela que países são oprimidos política e economicamente. Além disso, o compasso latino-americano é no sentido do ecocentrismo, ultrapassando a concepção do antropocentrismo e do puro humanismo. Esse giro ecocêntrico é decorrência do alerta sobre "os perigos da continuidade do modelo parasitário predominante de relações entre os seres humanos e a natureza" (MORAES, 2013, p. 130), que é vista como dominação e exploração, não se conjugando com uma ótica harmônica entre humano e natureza. Guarda-se, assim, relação com os valores da nova aliança entre o humano e a Terra, que de um pensamento arcaico assume a posição contemporânea na trilha da concepção indígena de veneração e benevolência à natureza (BOFF, 1996, p. 273-274).

Esse é o movimento do atual constitucionalismo latino-americano, sustentado a partir dos povos originários. Reconhecem-se formalmente, assim, as reivindicações sociais, com a abertura do espaço institucional para o exercício da cidadania por grupos outrora estranhos a esse processo. Enfatiza-se a democracia fundada no multiculturalismo, no pluralismo jurídico, na livre determinação dos povos (BELLO, 2012, p. 89-90).

A cidadania indígena é íntima ao novo constitucionalismo latino-americano, que adere a uma visão de pluralismo jurídico comunitário e participativo (e por que não socialista?). Nesse prisma que urge o enfrentamento das mazelas históricas do capitalismo dependente, fruto do (neo)colonialismo, tendo como tradução "a evolução do capitalismo e a incapacidade dos países latino-americanos de impedir sua incorporação dependente ao espaço econômico, cultural e político das sucessivas nações capitalistas hegemônicas", nas palavras de Fernandes (1975, p. 11). Relembra-se, diante disso, as maldições estruturais brasileiras ligadas à escravidão, a concentração fundiária e a extrema violência do Estado e das oligarquias, com ciclos democráticos curtos e instáveis desde a democracia censitária (ciclos nacionalistas autoritários e democráticos, ciclo militar totalitário decorrente do golpe civil militar, até a democracia espetacularizada que desmanchou com extrema facilidade a débil democracia formal, por meio da ação da mídia articulada com o setor oligárquico/financeiro). 
Conforme Santos (2009, p. 23-31), o conhecimento indígena está do "outro lado" da linha limítrofe do pensamento abissal. Ou seja, o lado do conhecimento tido como verdade pelo pensamento ocidental moderno, ocupado pela ciência, pela filosofia e pela teologia, é o lado visível, invisibilizando os demais conhecimentos que não se encaixam nos padrões dominantes. "Eles desaparecem como conhecimentos relevantes ou comensuráveis por se encontrarem para além do universo do verdadeiro e do falso". Contudo, esse é o espaço ocupado pelas zonas coloniais. A elite ocidental moderna nega o "outro lado" da linha com base em ideais e práticas impostas nas relações e interações políticas e culturais por ela protagonizadas.

Necessária uma reconstrução epistemológica conta o epistemicídio, rumo à descolonização. Isto é: a libertação do conhecimento, da reflexão e da comunicação em relação à racionalidade da modernidade europeia ocidental. Assumindo a heterogeneidade e a diversidade da realidade, o seu caráter contraditório e a sua legitimidade, deve-se considerar a cultura indígena como fonte de conhecimento. A racionalidade europeia moderna é reducionista e assume o controle do poder mundial. Então, é inexorável o abandono da prisão da colonização para que se atinja a descolonização epistemológica para uma comunicação intercultural, com um intercâmbio de experiências e significações fundado na nova racionalidade - que é legítima. Em suma, essa cosmovisão pretende a libertação das relações interculturais do enclausuramento ocasionado pela colonialidade, que provoca desigualdade, discriminação, exploração, dominação (QUIJANO, 1992, p. 18-20).

Saliente-se que:

[...] não está em questão a rejeição total da modernidade, mas sim o convite à observação e à construção de modernidades alternativas ao único modelo ocidental. Já a desconsideração dos aspectos econômicos em detrimento dos aspectos culturais não pode ser afirmada, uma vez que a própria noção de colonialidade está assentada na denúncia ao capitalismo e que a produção passada e presente de muitos dos seus autores carregam as influências de teorias preocupadas com a exploração/opressão econômica - libertação, dependência, sistema-mundo (BALLESTRIN, 2013, p. 111). 
No Brasil, grande parte dos indígenas foi dizimada no processo de colonização europeia, e os sobreviventes lutavam (e ainda lutam) para assim se manterem (CORRÊA; OLIVEIRA, 2007, p. 30). Na atualidade, as mobilizações indígenas estão associadas aos movimentos étnicos oriundos de países da América Latina, a partir dos anos 70. Inobstante, o custo do transporte, as dimensões do território brasileiro, a dispersão espacial da população indígena, a diversidade de contextos regionais e o autoritarismo estatal brasileiro no tratamento das questões indígenas dificultam a consolidação de movimentos indígenas de âmbito nacional (NEVES, 2003, p. 115).

Logo, o novo pluralismo "deve também se firmar como alternativa ao pluralismo policêntrico infrajurídico, construído por uma manipulação de interesses, mediante estatutos jurídicos dirigidos, por exemplo, no caso brasileiro, aos povos indígenas" (VÉRAS NETO, 2010, p. 165), porquanto estatutos legais que mantêm a ideologia não emancipatória ou anticidadã corroboram a versão opressora e conservadora que impera no cenário neoliberal e de contexto globalizado no âmbito brasileiro. A norma jurídica como empecilho à libertação e como fonte de manutenção da estrutura pragmática que tolhe a perspectiva revolucionária serve aos interesses dominantes, perpetuando a opressão.

\section{CIDADANIA INDÍGENA E ESTATUTO Do ÍNDIO}

A Constituição brasileira destina especialmente aos indígenas o Capítulo VIII ("Dos Índios"), do Título VIII ("Da ordem social”), artigos $231^{2}$ e $232^{3}$. Basicamente, reconhece-se aos povos originários a cultura, a organização social, a língua, a tradição e o direito sobre as terras (inalienáveis e indisponíveis, cujas relativas pretensões aos direitos são imprescritíveis), estabelecendo aos indígenas, suas comunidades e organizações, legitimidade processual para defesa judicial de seus direitos e interesses.

Ainda, o artigo 215, caput, da Constituição brasileira (1988), estabelece que "o Estado garantirá a todos o pleno exercício dos direitos culturais e acesso às fontes da cultura nacional, e apoiará e incentivará 
a valorização e a difusão das manifestações culturais", e, segundo o seu § 10, "o Estado protegerá as manifestações das culturas populares, indígenas e afro-brasileiras, e das de outros grupos participantes do processo civilizatório nacional".

A cidadania indígena não exclui a incidência dos demais direitos, como se ao povo indígena fosse reservada uma área legislativa própria, mas excludente (GUARANY, 2006, p. 161). A cidadania indígena se detém é na observância das peculiaridades dos povos originários, que não são compatíveis com os vetores hegemônicos europeus ocidentais, de modo que a imposição desses valores vão de encontro, em última instância, à dignidade humana dos indígenas.

No entanto, "ainda há uma grande diferença entre o tratamento constitucional brasileiro conferido aos direitos indígenas e o modelo de 'cidadania indígena' previsto pela ordenação internacional" (BELLO, 2012, p. 95). O Estado brasileiro não abre espaço para o ingresso do pluralismo jurídico e do Estado pluricultural e plurinacional:

Enquanto no Brasil continua a ser adotado apenas o modelo do Estado-nação (ou mononacional), que se limita a assegurar alguns direitos culturais a certos grupos étnicos, prepondera no atual constitucionalismo latino-americano a tendência do modelo jurídico do Estado intercultural e plurinacional, que já demonstra circulação entre Bolívia e Equador, temperada pelo modelo intermediário da Venezuela, que conjuga o Estado Democrático e Social de Direito com o reconhecimento de sua sociedade como multiétnica e pluricultural (BELLO, 2012, p. 120-121)

A Convenção no 169 da Organização Internacional do Trabalho - OIT, sobre Povos Indígenas e Tribais, de 27 de junho de 1989, promulgada pelo Decreto Presidencial no 5.051, de 19 de abril de 2004, menciona que se deve reconhecer "as aspirações desses povos a assumir o controle de suas próprias instituições e formas de vida e seu desenvolvimento econômico, e manter e fortalecer suas identidades, línguas e religiões, dentro do âmbito dos Estados onde moram" (preâmbulo). Outrossim, nessa mesma perspectiva do multiculturalismo ${ }^{4}$, a Convenção no 169 da OIT obtempera que "em diversas partes do mundo esses povos não podem gozar dos direitos humanos fundamentais no mesmo grau que o 
restante da população dos Estados onde moram e que suas leis, valores, costumes e perspectivas têm sofrido erosão freqüentemente" (preâmbulo). A orientação da Convenção no 169 da OIT, no aspecto geral, é no sentido de preservar a identidade cultural dos indígenas, vedando a interferência estatal e reconhecendo a sua autodeterminação. 0 artigo 7ํ, 1 e 3, são exemplo disso:

Artigo 7ํ. 1. Os povos interessados deverão ter o direito de escolher suas próprias prioridades no que diz respeito ao processo de desenvolvimento, na medida em que ele afete as suas vidas, crenças, instituições e bem-estar espiritual, bem como as terras que ocupam ou utilizam de alguma forma, e de controlar, na medida do possível, o seu próprio desenvolvimento econômico, social e cultural. Além disso, esses povos deverão participar da formulação, aplicação e avaliação dos planos e programas de desenvolvimento nacional e regional suscetíveis de afetá-los diretamente. [...] 3. Os governos deverão zelar para que, sempre que for possível, sejam efetuados estudos junto aos povos interessados com o objetivo de se avaliar a incidência social, espiritual e cultural e sobre o meio ambiente que as atividades de desenvolvimento, previstas, possam ter sobre esses povos. Os resultados desses estudos deverão ser considerados como critérios fundamentais para a execução das atividades mencionadas.

A Declaração das Nações Unidas sobre os Direitos dos Povos Indígenas, aprovada em 2007, por sua vez, também se inclina à autodeterminação dos indígenas, cujo respeito à respectiva cultura e modo de vida é elemento indissociável para tanto ${ }^{5}$. 0 artigo $3^{\circ}$ ratifica que "os povos indígenas têm direito à autodeterminação. Em virtude desse direito determinam livremente sua condição política e buscam livremente seu desenvolvimento econômico, social e cultural". Como suprassumo do reconhecimento do respeito à multiculturalidade dos povos originários e do pluralismo jurídico, o artigo 5o aduz que "os povos indígenas têm o direito de conservar e reforçar suas próprias instituições políticas, jurídicas, econômicas, sociais e culturais, mantendo ao mesmo tempo seu direito de participar plenamente, caso o desejem, da vida política, econômica, social e cultural do Estado". Por outro lado, o artigo 33 deixa nítido que "os povos indígenas têm o direito de determinar sua própria identidade ou composição conforme seus costumes e tradições. Isso não 
prejudica o direito dos indígenas de obterem a cidadania dos Estados onde vivem". Tudo porque se reconhece

[...] o fato de os povos indígenas terem sofrido injustiças históricas como resultado, entre outras coisas, da colonização e da subtração de suas terras, territórios e recursos, o que lhes tem impedido de exercer, em especial, seu direito ao desenvolvimento, em conformidade com suas próprias necessidades e interesses (preâmbulo).

O Estatuto do Índio, todavia, que é anterior à Constituição brasileira - foi instituído pela Lei no 6.001, de 19 de dezembro de 1973 -, "regula a situação jurídica dos índios ou silvícolas e das comunidades indígenas, com o propósito de preservar a sua cultura e integrá-los, progressiva e harmoniosamente, à comunhão nacional" (artigo 1ํㅜ caput). Ressalta-se que o Estatuto pretende "assegurar aos índios a possibilidade de livre escolha dos seus meios de vida e subsistência" (artigo 2oㅡㄹ inciso IV), "garantir aos índios a permanência voluntária no seu habitat, proporcionando-lhes ali recursos para seu desenvolvimento e progresso (artigo $2^{\circ}$, inciso V), e consagrar que se respeite, "no processo de integração do índio à comunhão nacional, a coesão das comunidades indígenas, os seus valores culturais, tradições, usos e costumes" (artigo $2^{\circ}$, inciso VI). Dispõe, ainda, o Estatuto do Índio:

Art 4ํ․ Os índios são considerados:

I - Isolados - Quando vivem em grupos desconhecidos ou de que se possuem poucos e vagos informes através de contatos eventuais com elementos da comunhão nacional;

II - Em vias de integração - Quando, em contato intermitente ou permanente com grupos estranhos, conservam menor ou maior parte das condições de sua vida nativa, mas aceitam algumas práticas e modos de existência comuns aos demais setores da comunhão nacional, da qual vão necessitando cada vez mais para o próprio sustento;

III - Integrados - Quando incorporados à comunhão nacional e reconhecidos no pleno exercício dos direitos civis, ainda que conservem usos, costumes e tradições característicos da sua cultura.

Ribeiro (1993, p. 432-433) menciona uma classificação de quatro graus de contato do indígena com a "sociedade", que são similares à ca- 
tegorização legal: os isolados vivem em zonas distantes da "sociedade", e os contatos com os "civilizados" são acidentais e raros, sendo tais indígenas arredios e hostis. As respectivas tribos são "as únicas que mantêm completa autonomia cultural”. Os indígenas em contato intermitente são aqueles cuja "sociedade" está em processo de aproximação, com leve influência dos traços culturais dos "civilizados", enquanto os em contato permanente "já perderam a sua autonomia sócio-cultural, pois se encontram em completa dependência da economia regional para o suprimento de artigos tornados indispensáveis", remanescendo apenas os costumes compatíveis com a nova condição, embora modificados, e "a população indígena tende a diminuir, chegando algumas tribos a índices tão baixos que tornam inoperante a antiga organização social". Os integrados, por fim, são os indígenas "ilhados em meio à população nacional", ultrapassada a experimentação dos processos retromencionados:

Poderiam ser confundidos com seus vizinhos neobrasileiros, se eles próprios não estivessem certos de que constituem um povo à parte, não guardassem uma espécie de lealdade a essa identidade étnica e se não fossem definidos, vistos e discriminados como "índios". (RIBEIRO, 1993, p. 433-434)

Gize-se ainda, quanto aos dispositivos do Estatuto do Índio, o artigo 5o, parágrafo único, segundo o qual "o exercício dos direitos civis e políticos pelo índio depende da verificação das condições especiais estabelecidas nesta Lei e na legislação pertinente", e o artigo 20, § 1ํo, alíneas "d" e "f", que estabelece que "em caráter excepcional e por qualquer dos motivos adiante enumerados, poderá a União intervir, se não houver solução alternativa, em área indígena, determinada a providência por decreto do Presidente da República”, "para a realização de obras públicas que interessem ao desenvolvimento nacional" e "para a exploração de riquezas do subsolo de relevante interesse para a segurança e o desenvolvimento nacional".

O plano até então traçado vai de encontro a "uma nova hermenêutica social de descolonização do etnocentrismo jurídico, capaz de desconstruir saberes jurídicos oficiais, subentendidos em institutos jurídicos conservadores" (VÉRAS NETO, 2010, p. 168), como ocorreria com a adoção do 
saber jurídico pluralista e coletivista dos indígenas, opondo-se, logo, a uma construção dogmática excludente. 0 Estatuto do Índio, entretanto, parece ter menosprezado isso.

De fato, malgrado não se olvide de sua importância jurídica, lançando olhares sobre a população originária do Brasil com inegáveis influências positivas para os indígenas nacionais, denota-se que o Estatuto do Índio assimila o povo originário do Brasil como "bárbaro", que deve ser inserido na "sociedade". Conforme Zea (1990, p. 23-30), bárbaro acaba sendo aquele sem legitimidade para produzir a "verdade", de cultura desvalorizada - inclusive a linguagem (balbucia). 0 bárbaro é marginalizado, não ocupando o centro cultural. A historicidade do bárbaro não é valorizada pois não se coaduna com o padrão cultural dos "civilizados". Precisa, por isso, ser domesticado, aculturado ${ }^{6}$, apreender a maneira não bárbara de se portar, agir, falar, produzir, viver, sob pena de permanecer bárbaro ${ }^{7}$.

Nos primórdios do período colonial, pairava sobre o indígena a dúvida acerca da sua natureza humana. A consequência disso influenciava o tratamento legal, as medidas políticas, enfim, toda forma de diálogo ou dominação para com o indígena. Preponderava a concepção de que os povos originários eram brutos, indolentes, semibestas. Diante disso, a justificativa colonizadora se apoiava na ideia de que os indígenas eram incapazes e dependiam da tutela do Estado e da Igreja (COLAÇO, 2005, p. 84-92).

Não obstante se tenha posteriormente considerado o indígena como humano, não fora abandonada a concepção de que ele era inferior e dependente do europeu. Chegou-se a pregar a submissão total do indígena ao europeu, e que aqueles não detinham o discernimento suficiente para se autocompreenderem como humanos. 0 efeito derivado atingiu as normas civilizadoras (oficiais e eclesiásticas) protecionistas. A "incapacidade" indígena desencadeou um arcabouço legislativo que circundava tais premissas. (COLAÇO, 2005, p. 92-97)

Nessa lógica, a Lei no 5.371, de 5 de dezembro de 1967, que institui a Fundação Nacional do Índio - FUNAI, disciplina que são algumas das finalidades da FUNAI o "resguardo à aculturação espontânea do índio, de forma a que sua evolução sócio-econômica se processe a salvo de mudanças bruscas" (artigo 1ํ, inciso I, alínea "d"), e a promoção da "educação 
de base apropriada do índio visando à sua progressiva integração na sociedade nacional" (artigo 1ํㅡㄹ inciso V).

O Estado Brasileiro, historicamente, reserva aos seus povos originários “apenas duas possibilidades: 1) 'isolados da civilização', como sociedades paradas no tempo; 2) 'integrados à civilização', como cidadãos marginais à sociedade nacional”. A assunção dos indígenas como sujeitos ativos é instrumento para contraditar essa limitação, em prol de uma "democracia plural". Trata-se de uma proposta de um modelo societário diferente do ocidental tradicional, que teima em aceitar a coexistência de diferenças (NEVES, 2003, p. 145-146), precipuamente nos setores de poder.

Interpretando o Estatuto do Índio, fica claro que é o indígena que deve integrar a "civilização", e não o contrário. Ou se é reificado e, como um objeto, permite-se ser moldado pela estrutura hegemônica e, assim, adquirir o condão de ser considerado "integrado", ou se é mantido no estado de "bárbaro" e, portanto, incapacitado da aquisição do título de "civilizado".

A situação é mais complexa, porquanto "um índio que deixa de ser índio, que perde por completo a sua cultura, não será um branco, com tendência a se tornar um excluído, a viver às margens das grandes cidades". Por conseguinte, é salutar a manutenção de uma cultura viva, preservada para as próximas gerações, mormente no cenário mundial da globalização. (SPAREMBERGER; SANTOS, 2007, p. 109)

O Estado brasileiro oferece ao povo originário uma cidadania tutelada ${ }^{8}$, que é caracterizada como uma cidadania concedida pela elite econômico-política, que é cultivada por meio de clientelismos e paternalismos (DEMO, 1995, p. 6). Ou seja, é aquela cidadania não libertária, onde, pelo contrário, estimula-se e reforça-se veladamente a permanência do estágio de não cidadania plena do indivíduo e dos grupos, ou, então, proporciona-se uma cidadania previamente modelada, sem perspectivas de alterações profundas na sua estrutura essencial. ${ }^{9}$

O ingresso na "civilização" requer a aceitação da sua estrutura produtiva mercadológica, onde se preconiza o capital em detrimento da cidadania. 0 aprimoramento da cultura indígena, tal qual o próprio povo indígena assim o considere, não é aprovado pelo Estatuto do Índio. 
Em suma, os interesses indígenas devem corresponder ao "ingresso" na sociedade "civilizada", haja vista que outra alternativa será avaliada como "bárbara".

Esse pensamento sobre o indígena também é fruto de um Estatuto do Índio (e a Lei no 5.371/1967) que remonta ao período ditatorial brasileiro, e estruturado em referências integracionistas. A ideologia traduzida nas entrelinhas aponta para o intuito de eliminação gradual dos povos indígenas, cuja cultura deveria ser abandonada. (SCHNEIDER, 2015, p. 27-28) Além disso, a Constituição Federal brasileira "manteve o modelo estadocêntrico e passivo da cidadania, com pouca abertura para o multiculturalismo delgado e não reconheceu o pluralismo jurídico" (BELLO, 2012, p. 94).

Ademais, a proposta de Emenda Constitucional no 215/2000 aponta que o horizonte brasileiro é de retrocesso, especialmente no que tange às terras indígenas. 0 artigo 231, $\S 4$ 으, da Constituição brasileira, que se refere às terras tradicionalmente ocupadas pelos povos indígenas, passaria a vigorar com a seguinte redação ${ }^{10}$ : "as terras de que trata este artigo, após a respectiva demarcação aprovada ou ratificada pelo Congresso Nacional, são inalienáveis e indisponíveis, e os direitos sobre elas, imprescritíveis" (BRASIL, 2000, p. 16399). Além disso, pretende-se com a citada emenda o acréscimo do inciso XV no artigo 49 do texto constitucional, com a subsequente renumeração dos demais incisos, para que conste como competência exclusiva do Congresso Nacional "aprovar a demarcação das terras tradicionalmente ocupadas pelos índios e ratificar as demarcações já homologadas" (BRASIL, 2000, p. 16399).

Parece que distintos interesses se sobrepuseram aos direitos indígenas, de modo que a inalienabilidade e a indisponibilidade das ditas terras, e a imprescritibilidade das pretensões referentes aos direitos, estão na iminência de pressuporem a aprovação da demarcação aprovada ou ratificada pelo Congresso Nacional. É um notório entrave burocrático que oculta desígnios obscurecidos pela emenda constitucional, entre eles o de não tornar protegidas as terras indígenas para que a exploração econômica não seja inviabilizada, representando mais uma expressão da inobservância do interculturalismo pelo Estado brasileiro quanto a seu povo originário. 
Por essa razão que se ratifica, no plano constitucional, conforme as palavras de Véras Neto (2010, p. 168), que "o constitucionalismo formal e abstrato deve ser substituído por um projeto de constitucionalismo material, originário e insurgente", assumindo as organizações representativas singular papel revolucionário para se pretender alcançar uma democracia direta e participativa ("democratização da democracia"), sob a luz da pluridimensionalidade dos direitos humanos. 0 artigo 23 da Declaração das Nações Unidas sobre Direitos dos Povos Indígenas é partidário desse entendimento:

Os povos indígenas têm o direito de determinar e elaborar prioridades e estratégias para o exercício do seu direito ao desenvolvimento. Em especial, os povos indígenas têm o direito de participar ativamente da elaboração e da determinação dos programas de saúde, habitação e demais programas econômicos e sociais que lhes afetem e, na medida do possível, de administrar esses programas por meio de suas próprias instituições.

Dessa forma, estar-se-á privilegiando uma cidadania plena, como "competência humana de fazer-se sujeito, para fazer história própria e coletivamente organizada", e a identidade cultural é crucial para tal desiderato (DEMO, 1995, p. 1). Depreciar a cultura identitária ${ }^{11}$ de um povo é subjugá-lo, ainda que isso ocorra ocultamente, sob as vestes de "integração nacional". Por isso que a cidadania ampliada,

[...] inspirada na sua origem pela luta pelos direitos humanos (e contribuindo para a progressiva ampliação do seu significado) como parte da resistência contra a ditadura, essa concepção buscava implementar um projeto de construção democrática, de transformação social, que impõe um laço constitutivo entre cultura e política. Incorporando características de sociedades contemporâneas, tais como o papel das subjetividades, o surgimento de sujeitos sociais de um novo tipo e de direitos também de novo tipo, bem como a ampliação do espaço da política, esse projeto reconhece e enfatiza o caráter intrínseco da transformação cultural com respeito à construção da democracia. Nesse sentido, a nova cidadania inclui construções culturais, como as subjacentes ao autoritarismo social como alvos políticos fundamentais da democratização. Assim, a redefinição da noção de cidadania, formulada pelos movimentos sociais, expressa não somente uma estratégia política, mas também uma política cultural. (DAGNINO, 2004:103-104) 
A cidadania ampliada redefine a ideia de "direitos" como o "direito a ter direitos", isto é, sem limitação a previsões legais, a direitos previamente estatuídos, à efetiva implementação de direitos formais abstratos. Em vez disso, criam-se novos direitos através de lutas específicas e da prática política concreta, merecendo destaque o direito à diferença como aprofundamento e especialização do direito à igualdade. Por outro lado, não se vincula a cidadania ampliada à estratégia das classes dominantes, nem ao "Estado de incorporação política gradual dos setores excluídos, com objetivo de uma maior integração social ou como uma condição legal e política necessária para a instalação do capitalismo". Sujeitos sociais ativos emergem e definem (eles próprios, e não por tutela) o que consideram como direitos, e lutam pelo respectivo reconhecimento, em um processo de "baixo" para "cima". (DAGNINO, 2004, p. 104) "A cidadania pressupõe, portanto, a igualdade de oportunidades e de condições fundamentais iguais para todos, respeitadas as peculiaridades dos indivíduos como, no caso dos indígenas, a preservação de seu modo de vida" (CORRÊA; OLIVEIRA, 2007, p. 28).

Ocorre que o hodierno contexto da globalização neoliberal, inserida na tendência expansiva do modo de produção capitalista, é consubstanciado em práticas sistemáticas antidemocráticas, reduzindo tudo a valores de troca e dotando-o de uma racionalidade particularista-capitalista. Daí a relevância dos processos dinâmicos sociais, políticos, econômicos e culturais para o desenvolvimento dos direitos humanos. (FLORES, 2005, p. 142-143)

A "proposta histórico-social de um pluralismo comunitário-participativo como novo modelo político e jurídico de legitimidade, caracterizado por formas múltiplas de produção de juridicidade e por modalidades democráticas e emancipatórias de práticas sociais" (WOLKMER, 2001, p. 24) é de urgente concretização, máxime porque "a hipótese de emancipação de valores indígenas, como projeto de multiculturalismo emergente, apesar de muito discutida, não se encontra viabilizada" (CORRÊA; OLIVEIRA, 2007, p. 36), e o Estatuto do Índio não oferece uma cidadania indígena plena. 


\section{CONSIDERAÇÕES FINAIS}

A visão mononacional do Estado brasileiro reflete no sentido da política dirigida aos povos originários: uma política de manutenção da hegemonia eurocêntrica, opressiva, não participativa e em detrimento de uma cidadania ampliada. 0 Estatuto do Índio simboliza claramente tal assertiva, por expressões que denotam a pretensão de aculturamento sobre o povo indígena.

É medida imperativa, dessarte, a mudança de rumo do cenário jurídico-social brasileiro, com o escopo de, sob os ares do constitucionalismo latino-americano, abandonar-se a tentativa de assemelhar-se à cultura europeia para, inversamente, valorizar a riqueza cultural nativa (um giro decolonial). No plano interno, a conscientização de que o indígena não é bárbaro e que a sua identidade cultural é suporte do pluralismo jurídico e da cidadania indígena é o primeiro passo para uma democracia participativa quanto aos povos originários.

O Estatuto do Índio é vetusto e necessita de reformulação para absorver as concepções do interculturalismo, e abandonar a lógica do "ingresso na sociedade civilizada", para que o povo indígena não seja subalternizado. A luta contra-hegemônica perpassa pela participação do povo indígena nos espaços públicos decisórios e na construção autônoma de sua própria história, enfrentando-se o neoliberalismo que ameaça a sobrevivência da cultura indígena em nome do desenvolvimento econômico.

Para o aperfeiçoamento da democracia brasileira, necessária a revogação, inicialmente, dos preceitos normativos que obstam ou pretendem tolher a cidadania material indígena, para que, a partir daí, articule-se política e socialmente o respeito e a valorização da cultura indígena e reformule-se a ótica sobre as diferenças para preconizar a solidariedade, a interculturalidade e a pluralidade dos povos originários do Brasil. Trata-se de questão central para a construção de novos espaços para a cidadania indígena, sonegados pela ordem oligárquica neoliberal brasileira dentro do contexto do capitalismo periférico transformado em verdadeira República das bananas. 


\section{Notas}

1 Cultura é "um sistema coletivo de sentidos, signos, valores, práticas sociais, processos sociopolíticos, criados historicamente por grupos sociais para estruturar as suas identidades coletivas, como referência vital do seu dia a dia nas relações entre si e com outros grupos" (KROHLING, 2009, p. 104).

2 Art. 231. São reconhecidos aos índios sua organização social, costumes, línguas, crenças e tradições, e os direitos originários sobre as terras que tradicionalmente ocupam, competindo à União demarcá-las, proteger e fazer respeitar todos os seus bens. § 1․․ São terras tradicionalmente ocupadas pelos índios as por eles habitadas em caráter permanente, as utilizadas para suas atividades produtivas, as imprescindíveis à preservação dos recursos ambientais necessários a seu bem-estar e as necessárias a sua reprodução física e cultural, segundo seus usos, costumes e tradições. $\S 2^{\circ}$. As terras tradicionalmente ocupadas pelos índios destinam-se a sua posse permanente, cabendo-lhes o usufruto exclusivo das riquezas do solo, dos rios e dos lagos nelas existentes. § $3^{\circ}$. 0 aproveitamento dos recursos hídricos, incluídos os potenciais energéticos, a pesquisa e a lavra das riquezas minerais em terras indígenas só podem ser efetivados com autorização do Congresso Nacional, ouvidas as comunidades afetadas, ficando-lhes assegurada participação nos resultados da lavra, na forma da lei. § $4 \%$. As terras de que trata este artigo são inalienáveis e indisponíveis, e os direitos sobre elas, imprescritíveis. § 5‥ É vedada a remoção dos grupos indígenas de suas terras, salvo, "ad referendum" do Congresso Nacional, em caso de catástrofe ou epidemia que ponha em risco sua população, ou no interesse da soberania do País, após deliberação do Congresso Nacional, garantido, em qualquer hipótese, o retorno imediato logo que cesse o risco. $\S 6$ ․ São nulos e extintos, não produzindo efeitos jurídicos, os atos que tenham por objeto a ocupação, o domínio e a posse das terras a que se refere este artigo, ou a exploração das riquezas naturais do solo, dos rios e dos lagos nelas existentes, ressalvado relevante interesse público da União, segundo o que dispuser lei complementar, não gerando a nulidade e a extinção direito a indenização ou a ações contra a União, salvo, na forma da lei, quanto às benfeitorias derivadas da ocupação de boa fé. § 7ํ․ Não se aplica às terras indígenas o disposto no art. $174, \S 3^{\circ}$ e e $\S 4^{\circ}$.

3 Art. 232. Os índios, suas comunidades e organizações são partes legítimas para ingressar em juízo em defesa de seus direitos e interesses, intervindo o Ministério Público em todos os atos do processo.

4 O artigo 8o, 2, da Convenção no 169 da OIT, parece refrear a pretensão ao interculturalismo quando tende ao caráter hegemônico e universalista dos direitos humanos (ainda que abra espaço ao diálogo para a ponderação dos interesses), pois aduz que "esses povos deverão ter o direito de conservar seus costumes e instituições próprias, desde que eles não sejam incompatíveis com os direitos fundamentais definidos pelo sistema jurídico nacional nem com os direitos humanos internacionalmente reconhecidos. Sempre que for necessário, deverão ser estabelecidos procedimentos para se solucionar os conflitos que possam surgir na aplicação deste principio". 0 artigo 34 ainda diz que "a natureza e o alcance das medidas que sejam adotadas para por em efeito a presente Convenção deverão ser determinadas com flexibilidade, levando em conta as condições próprias de cada país".

5 Embora igualmente o caráter universal dos direitos humanos seja respaldado nas entrelinhas da Declaração, como se nota do preâmbulo que alude que "o reconhecimento dos direitos dos povos indígenas na presente Declaração fomentará relações harmoniosas e de cooperação entre os Estados e os povos indígenas, baseadas nos princípios da justiça, da democracia, do respeito aos direitos humanos, da não-discriminação e da boa-fé".

6 próprio artigo 52 do Estatuto do Índio determina que "será proporcionada ao índio a formação profissional adequada, de acordo com o seu grau de aculturação".

7 O Estatuto do Índio, no seu artigo 53, estipula que "o artesanato e as indústrias rurais serão estimulados, no sentido de elevar o padrão de vida do índio com a conveniente adaptação às condições técnicas modernas". 
80 próprio artigo 7ํ do Estatuto do Índio prescreve que “os índios e as comunidades indígenas ainda não integrados à comunhão nacional ficam sujeito ao regime tutelar estabelecido nesta Lei”.

9 A tutela, que deveria garantir e proteger os direitos indígenas, mais serviu como instrumento de coação para limitá-los, transformando-se em forte mecanismo de dependência e anulação cultural, furtando-lhes a liberdade individual e a independência coletiva. [...] Deseja-se, através do conhecimento das mazelas do passado, seja possível que a questão da incapacidade e da tutela indígena, ainda vigente no Brasil e em outros países da América, e o trabalho das missões religiosas em aldeias indígenas no interior do país, sejam rediscutidos e reavaliados, [...] possibilitando até sugestões à legislação indígena atual. (COLAÇO, 2005, p. 210)

10 A atual redação do artigo 231, § 4ํㅡ, da Constituição Federal, assim dispõe: “As terras de que trata este artigo [as terras tradicionalmente ocupadas pelos índios] são inalienáveis e indisponíveis, e os direitos sobre elas, imprescritíveis".

11 "As áreas de periferia que se organizam e estabelecem modelos de sociedade providência, que é expresso no comunitarismo decorrente da exclusão, formação de organizações autogestionárias, dentro da economia solidária, ou, por intermédio de novos polos promissores de emancipação libertadora representados pela auto-organização dos povos indígenas, da floresta e quilombolas, que podem se libertar da exclusão social, mantendo o direito à identidade sonegado pelo pluralismo policêntrico infrajurídico, estatal assistencialista contemporâneo." (VÉRAS NETO, 2010, p. 168)

\title{
REFERÊNCIAS
}

\author{
BALLESTRIN, Luciana. América Latina e o giro decolonial. Revista Brasileira \\ de Ciência Política, Brasília, n. 11, p. 89-117, mai./ago. 2013.
}

\author{
BELLO, Enzo. A cidadania no constitucionalismo latino-americano. Caxias \\ do Sul: Educs, 2012.
}

BOFF, Leonardo. Ecología: grito de la Tierra, grito de los pobres. Tradução de Juan Carlos Rodríguez Herranz. Madrid: Trotta, 1996.

BRASIL. Diário da Câmara dos Deputados. Brasília, n. 71, 19 abr. 2000. Disponível em: http://imagem.camara.gov.br/Imagem/d/pdf/DCD19ABR2000. pdf\#page=69. Acesso em: 3 jul. 2016.

CASTRO, Eduardo Viveiro de. A inconstância da alma selvagem: e outros ensaios de antropologia. São Paulo: Cosac Naify, 2002.

COLAÇO, Thaís Luzia. Incapacidade indígena: tutela religiosa e violação do direito guarani nas missões Jesuíticas. Curitiba: Juruá, 2005.

CORRÊA, Darcísio; OLIVEIRA, Janassana Indiara Almeida de. A questão da cidadania na reserva indígena do Guarita. In: CORRÊA, Darcísio et. al (Org.). 
Cidadania, biodiversidade e identidade cultural na reserva indígena do Guarita. Ijuí: Editora Unijuí, 2007.

COUTINHO, Carlos Nelson. A democracia como valor universal. In: SILVEIRA, Ênio et al. (Org.). Encontros com a civilização brasileira. Rio de Janeiro: Civilização Brasileira, 1979. p. 33-47.

DAGNINO, Evelina. ¿Sociedade civil, participação e cidadania: de que estamos falando?. In: Daniel Mato (Org.). Políticas de ciudadanía y sociedad civil en tiempos de globalización. Caracas: FACES, Universidad Central de Venezuela, 2004. p. 45-59.

DEMO, Pedro. Cidadania tutelada e cidadania assistida. Campinas: Autores Associados, 1995.

FERNANDES, Florestan. Capitalismo dependente e classes sociais na América Latina. 2. ed. Rio de Janeiro: Zahar Editores, 1975.

FLORES, Joaquín Herrera. Los derechos humanos como productos culturales: crítica del humanismo abstrato. Madrid: Catarata, 2005.

GUARANY, Vilmar Martins Moura. Desafios e perspectivas para a construção e o exercício da cidadania indígena. In: ARAÚJO, Ana Valéria et. al. (Org.). Povos indígenas e a Lei dos "Brancos": o direito à diferença. Brasília: Ministério da Educação, Secretaria de Educação Continuada, Alfabetização e Diversidade, 2006. p. 146-166.

KROHLING, Aloísio. Direitos humanos fundamentais: diálogo intercultural e democracia. São Paulo: Paulus, 2009.

LAKATOS, Eva Maria; MARCONI, Marina de Andrade. Metodologia do trabalho científico: procedimentos básicos, pesquisa bibliográfica, projeto e relatório, publicações e trabalhos científicos. 7. ed. São Paulo: Atlas, 2012.

LÉVI-STRAUSS, Claude. o pensamento selvagem. Tradução de Tânia Pellegrini. Campinas: Papirus, 1989. 
LUCAS, Doglas Cesar. Prefácio. In: CORRÊA, Darcísio et. al (Org.). Cidadania, biodiversidade e identidade cultural na reserva indígena do Guarita. Ijuí: Editora Unijuí, 2007.

MELATTI, Julio Cezar. Índios do Brasil. 4. ed. São Paulo: Hucitec, 1983.

MORAES, Germana de Oliveira. 0 constitucionalismo ecocêntrico na América Latina, o Bem Viver e a nova visão das águas. Revista da Faculdade de Direito da Universidade Federal do Ceará. Fortaleza, v. 34, n. 1, p. 123-155, jan./ jun. 2013.

NEVES, Lino João de Oliveira. Olhos mágicos do Sul (do Sul): lutas contra-hegemônicas dos povos indígenas no Brasil. In: SANTOS, Boaventura de Sousa (Org.). Reconhecer para libertar: os caminhos do cosmopolitismo multicultural. Rio de Janeiro: Civilização Brasileira, 2003. p. 111-151.

PANIKKAR, Raimundo. Seria a noção de direitos humanos um conceito ocidental? In: BALDI, César Augusto (Org.) Direitos humanos na sociedade cosmopolita. Rio de Janeiro: Renovar, 2004. p. 205-238.

QUIJANO, Aníbal. Colonialidad y modernidad/racionalidad. Perú Indígena. v. 13, n. 29, p. 11-20, 1992.

RIBEIRO, Darcy. Os índios e a civilização: a integração das populações indígenas no Brasil moderno. 6. ed. Petrópolis: Vozes, 1993.

SANTOS, Boaventura de Sousa. Para além do pensamento abissal: das linhas globais a uma ecologia dos saberes. In: SANTOS, Boaventura de Sousa; MENESES, Maria Paula (Org.). Epistemologias do Sul. Coimbra: Almedina, 2009. p. 23-71.

SANTOS, Boaventura de Sousa; AVRITZER, Leonardo. Introdução: para ampliar o cânone democrático. In: SANTOS, Boaventura de Sousa (Org.). Democratizar a democracia: os caminhos da democracia participativa. Rio de Janeiro: Civilização Brasileira, 2002. p. 39-82.

SANTOS, Boaventura de Sousa; NUNES, João Arriscado. Introdução: para ampliar o cânome do reconhecimento, da diferença e da igualdade. In: SANTOS, Boaventura de Sousa (Org.). Reconhecer para libertar: os caminhos do 
cosmopolitismo multicultural. Rio de Janeiro: Civilização Brasileira, 2003. p. 25-68.

SCHNEIDER, Giselda Siqueira da Silva. 0 direito ao território enquanto condição para cidadania dos povos originários do Brasil. Rio Grande, 2015. (Dissertação apresentada ao Programa de Pós-Graduação em Direito - PPGD da Universidade Federal do Rio Grande - FURG como requisito parcial à obtenção do grau de Mestre em Direito). Rio Grande: Universidade Federal do Rio Grande, 2015.

SPAREMBERGER, Raquel Fabiana Lopes; SANTOS, Marcelo Loeblein dos. A proteção da biodiversidade e da identidade natural e cultural do indígena: em busca de sustentabilidade. In: CORRÊA, Darcísio et. al (Orgs.). Cidadania, biodiversidade e identidade cultural na reserva indígena do Guarita. Ijuí: Editora Unijuí, 2007.

VÉRAS NETO, Francisco Quintanilha. Pluralismo jurídico-comunitário participativo, emancipatório, libertador como projeto de combate ao monismo jurídico neoliberal na América Latina. Espaço Jurídico. Joaçaba, v. 11, n. 1, p. 149-185, jan./jun. 2010.

. Uma reflexão problematizadora da propriedade intelectual da biodiversidade e da busca de justiça ambiental dentro das recentes transformações constitucionais sul-americanas da Bolívia e do Equador como paradigmas representativos de uma embrionária utopia ecocivilizatória ecossocialista. In: BRAUNER, Maria Claudia Crespo; LOBATO, Anderson Orestes Cavalcante (Orgs.). Direito e justiça social: a construção jurídica dos direitos de cidadania. Rio Grande: Editora da Furg, 2015. p. 215-266.

WOLKMER, Antonio Carlos. Pluralismo jurídico: fundamentos de uma nova cultura no Direito. 3ae ed. rev. e atual. São Paulo: Alfa Omega, 2001.

WOLKMER, Antonio Carlos; FERRAZZO, Débora. Resignificação do conceito de democracia a partir de direitos plurais e comunitários latino-americanos. Revista Direitos Fundamentais e Democracia. Curitiba, v. 16, n. 16, p. 200 228, jul./dez. 2014.

ZEA, Leopoldo. Discurso desde la marginación y la barbarie. México: Fondo de Cultura Económica, 1990. 
Recebido em: 26-6-2017

Aprovado em: 20-11-2018

\section{Luciano Roberto Gulart Cabral Júnior}

Mestrando em Direito e Justiça Social no Programa de Pós-Graduação em Direito da Universidade Federal do Rio Grande (FURG). E-mail: lucianocabraljunior@ hotmail.com

\section{Francisco Quintanilha Véras Neto}

Doutor em Direito das Relações Sociais pela Universidade Federal do Paraná; professor do Programa de Mestrado em Direito e Justiça Social e do Curso de Graduação em Direito da Faculdade de Direito da Universidade Federal do Rio Grande (FURG).E-mail: quintaveras@gmail.com

Universidade Federal do Rio Grande, FURG. Pró-Reitoria de Pesquisa e PósGraduação, PROPESP. Faculdade de Direito, FaDir. Programa de Pós-Graduação em Direito, PPGD

Campus Carreiros - Av. Itália Km 8. 96203-000. Rio Grande - RS 
